\title{
A rare diagnosis with a common presentation: a case report on uterine sarcoma
}

\section{Rinda Naidu Kanukolanu, Ushadevi Gopalan*, Sivan Kumar Kumarapillai, Priyanka Pradeep}

Department of Obstetrics and Gynecology, Shri Sathya Sai Medical College and Research Institute, Ammapettai, Chengalpattu District, Tamil Nadu, India

Received: 30 January 2021

Accepted: 03 May 2021

*Correspondence:

Dr. Ushadevi Gopalan,

E-mail: ushag7@hotmail.com

Copyright: (c) the author(s), publisher and licensee Medip Academy. This is an open-access article distributed under the terms of the Creative Commons Attribution Non-Commercial License, which permits unrestricted non-commercial use, distribution, and reproduction in any medium, provided the original work is properly cited.

\section{ABSTRACT}

Uterine sarcomas are rare soft tissue tumors which constitute $3 \%$ to $7 \%$ of overall uterine malignancies. Endometrial stromal sarcoma (ESS) is a rare type of uterine sarcoma arising from the mesodermal component of the body of the uterus. It constitutes around $0.2 \%$ of all the uterine tumors. It primarily occurs in perimenopausal women. One third of cases are seen in postmenopausal women. The presentation is not very different from an abnormal uterine bleeding, abdominal pain or a mass effect. Here we discuss an interesting case of 70 years female with a very common presentation of utero-vaginal prolapse but turned out to be a very rare postoperative diagnosis of uterine sarcoma.

Keywords: Uterine sarcoma, Postmenopausal, Utero vaginal prolapse

\section{INTRODUCTION}

Uterine sarcomas are soft tissue tumors which are a rare group of neoplasias of corpus uteri. These are mesenchymal in origin and arise from uterine myometrium or connective tissue. They constitute about $3 \%$ to $7 \%$ of all the uterine malignancies and $<1 \%$ of all genital cancers. ${ }^{1}$ Most common age of occurrence is between 40 and 50 years and very rare before 30 years. $0.5 \%$ of fibroids undergo sarcomatous change.

Endometrial stromal sarcoma is one of the types of uterine sarcoma which is primarily seen in perimenopausal women between the age 45 and 50 years. Around one third of cases occur in postmenopausal women. There is no relationship with parity of the patient, associated diseases or any pelvic radiotherapy undergone previously.

The patients present with abnormal uterine bleeding, abdominal pain or a mass effect. Usually diagnosis is only by endometrial biopsy which is not very reliable. A retrospective study was conducted on 212 women who were diagnosed with uterine leiomyosarcoma over a period of 13 years. According to this study, they found that diagnosis of uterine sarcoma (leiomyosarcoma) was done by histopathological examination only post-operatively after the removal of the specimen for some other benign conditions. $^{2}$

\section{CASE REPORT}

A 70 years old postmenopausal women, para four, presented to gynaecology out-patient department with chief complaints of mass descending per vaginum for the past 10 years and low back ache for the past 3 months. She had four normal vaginal home deliveries and the last child birth was 44 years back. She had no other menstrual or post-menopausal bleeding or vaginal discharge. She is a known case of Type- 1 diabetes mellitus for the past three years and is on metformin tablet $500 \mathrm{mg}$ twice a day. She attained menopause at the age of 26 years after her last child birth for which she did not undergo any evaluation and the patient had no associated complaints. There was no relevant family history suggestive of malignancies. Her general physical examination was unremarkable. On systemic examination the patient had $3^{\text {rd }}$ degree UV prolapse with mild cystocele and moderate rectocele and enterocele. There were no ulcerations and pigmentations 
over the prolapsed mass and the cervix showed no abnormality. The UV prolapse was reducible and on per vaginal examination the uterus was atrophic, retroverted and mobile. There were no masses palpable on pelvic examination.

Patient was admitted and all the necessary routine investigations were done. Her ultrasound report showed normal study. Her pap smear report was negative for intraepithelial lesion or neoplasia. Pre-anaesthetic assessment was obtained and she was taken up for surgery. We performed vaginal hysterectomy with pelvic floor repair. Her post-operative period was uneventful and she was discharged on fifth post-operative day. The histopathological report revealed endometrial stromal sarcoma-low grade. Pathological stage: pT1 (Figure 1-4).

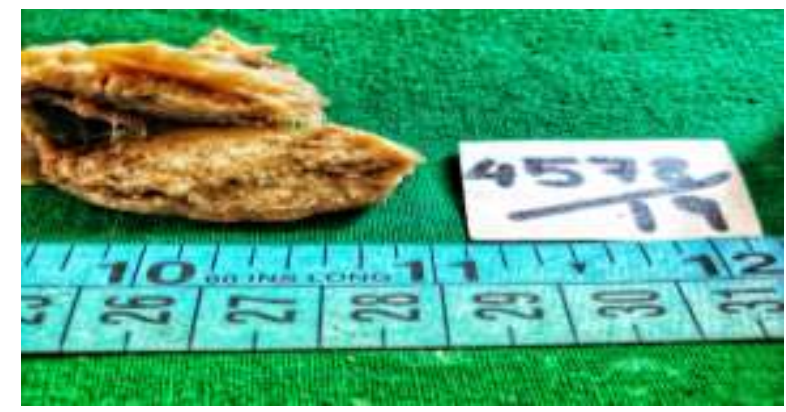

Figure 1: Cut section of the gross specimen.

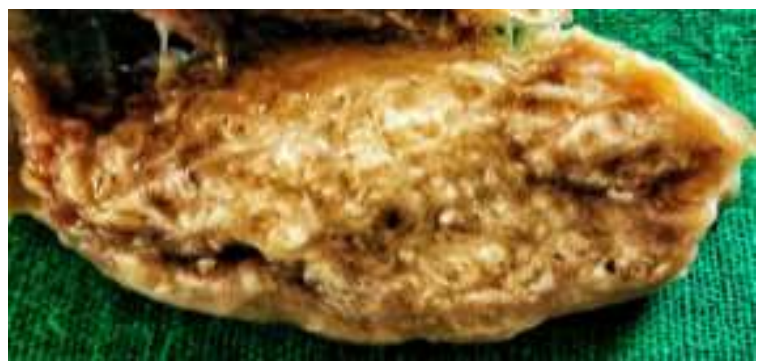

Figure 2: Magnified view of the cut surface of the hysterectomy specimen showing normal endometrium and subserosal myoma.

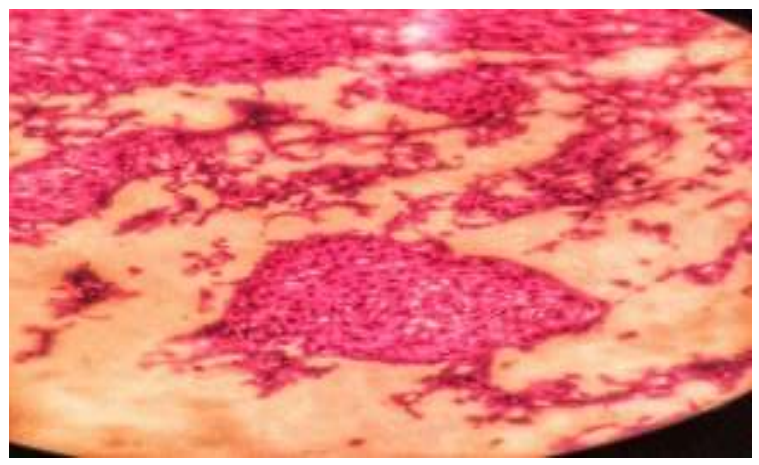

Figure 3: Histopathologic picture of endometrial stromal cells showing hypercellularity and mild nuclear atypia.

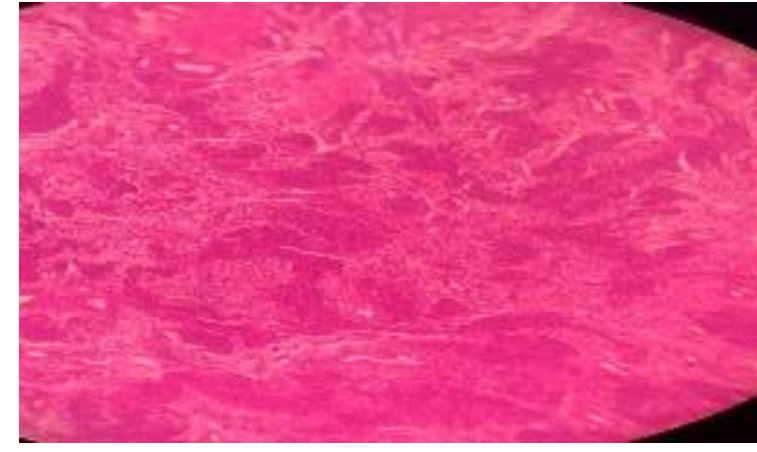

Figure 4: showing irregular sheets and nests of tumor cells extensively permeating the myometrium in tongue like fashion.

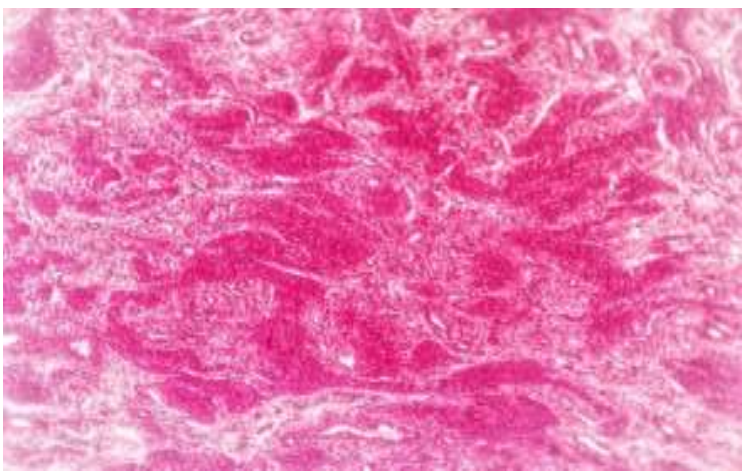

Figure 5: H\&E 10X view showing irregular sheets and nests of tumor cells extensively permeating the myometrium in tongue like fashion.

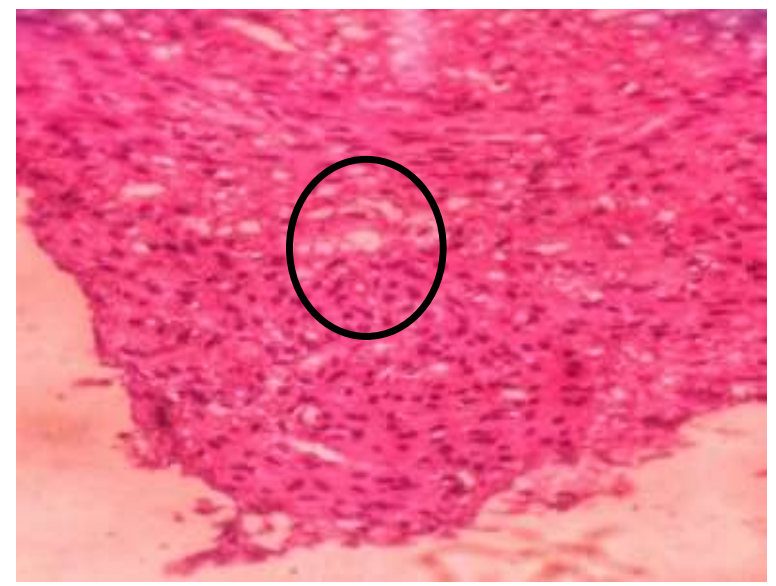

Figure 6: H\&E 40X showing oval to spindle shaped nuclei with scanty cytoplasm.

When the patient came for post-operative follow-up she was advised for a chest X-ray and MRI to rule out metastasis and secondaries but the MRI showed only inflammatory changes suggestive of post-operative status and negative for lymph node and distant metastases. She was referred to oncology department for further evaluation and management. The patient was thoroughly evaluated and was found to be negative for residual tumor and other 
metastases. She is under regular follow up and is disease free.

\section{DISCUSSION}

Uterine sarcomas have a poor prognosis, with higher incidence in black women when compared to white women. Though the exact etiology of the tumor development is poorly understood many possible factors have been associated with increased risk for development of uterine sarcoma like menopausal use of estrogens and progestins, oral contraceptive pills, obesity and use of tamoxifen. Factors like smoking and increased parity are related with decreased risk. ${ }^{3}$ The overall 5 years survival rate of this very aggressive tumor ranges between $17 \%$ and $55 \% .^{4}$

In most of the cases the pre-operative diagnosis will be uterine fibroid. ${ }^{5}$ The diagnosis in all such conditions is only by histopathological examination of the endometrial biopsy. But this is reliable in very few cases as the sampling is from endometrium but the tumor arises from myometrium. ${ }^{6}$ Though the recent imaging modalities like MRI and FDG-PET CT are employed for diagnosis but their use is limited because of rarity of the tumor. ${ }^{7}$

Treatment modalities will depend upon the type of tumor and their severity. Total hysterectomy with removal of tubes and ovaries on both the sides along with excision of grossly detectable lesions is the mainstay of treatment in low-grade ESS. Lymph node dissection is not routinely followed as there is low rate of metastasis into lymph nodes. Local irradiation can be considered in case the surgery is inadequate but chemotherapy was found not beneficial in these cases. Hormonal therapy gives response in $50 \%$ of patients with recurrences or metastases. Low grade ESS has good prognosis. High grade ESS and UUS have the same surgical treatment but the results are found to be poor with surgery alone. Hence adjuvant radiotherapy and chemotherapy are combined with surgical treatment but they are not responsive to hormonal therapy. ${ }^{8}$ Surgery is the mainstay of treatment for leiomyosarcoma. If the tumor spread is extrauterine then complete cytoreductive surgery along with metastatectomy has shown to improve survival. ${ }^{9}$ Similarly surgery is the standard treatment for adenosarcoma followed by post-operative adjuvant radiotherapy. ${ }^{10}$

\section{CONCLUSION}

The diagnosis of uterine sarcomas is quite challenging preoperatively as the patients clinically present with unclear and vague symptoms. The women are perimenopausal and about one third of the cases are postmenopausal. Most common presentation is an abnormal uterine bleeding and less conspicuous complaints like pain in the lower abdomen and pelvis and distension of the abdomen or pressure by an enlarging pelvic mass. High index of clinical suspicion is necessary in diagnosis of a uterine sarcoma which will otherwise be missed but if diagnosed early has a very good prognosis.

\section{Funding: No funding sources \\ Conflict of interest: None declared \\ Ethical approval: Not required}

\section{REFERENCES}

1. Angelo E, Prat J. Uterine sarcomas: a review. Gynecol Oncol. 2010;116(1):131-9.

2. Skorstad M, Kent A, Lieng M. Preoperative evaluation in women with uterine leiomyosarcoma. A nationwide cohort study. Acta Obstet Gynecol Scand. 2016;95(11):1228-34.

3. Kvale G, Heuch I, Ursin G. Reproductive factors and risk of cancer of the uterine corpus: a prospective study. Cancer Res. 1988;48(21):6217-21.

4. Prat J. FIGO staging for uterine sarcomas. Int $\mathbf{J}$ Gynaecol Obstet. 2009;104(3):177-8.

5. Prat J, Mbatani. Uterine sarcomas. Int J Gynaecol Obstet. 2015;131(2):105-10.

6. Wu TI, Yen TC, Lai CH. Clinical presentation and diagnosis of uterine sarcoma, including imaging. Best Pract Res Clin Obstet Gynaecol. 2011;25(6):681-9.

7. Tanaka YO, Nishida M, Tsunoda H, Okamoto Y, Yoshikawa H. Smooth muscle tumors of uncertain malignant potential and leiomyosarcomas of the uterus: MR findings. J Magn Reson Imaging. 2004;20(6):998-1007.

8. Trope CG, Abeler VM, Kristensen GB. Diagnosis and treatment of sarcoma of the uterus. A review. Acta Oncol. 2012;51(6):694-705.

9. Ricci S, Stone RL, Fader AN. Uterine leiomyosarcoma: Epidemiology, contemporary treatment strategies and the impact of uterine morcellation. Gynecol Oncol. 2017;145(1):208-16.

10. Nathenson MJ, Ravi V, Fleming N, Wang WL, Conley A. Uterine Adenosarcoma: a Review. Curr Oncol Rep. 2016;18(11):68.

Cite this article as: Kanukolanu RN, Gopalan U, Kumarapillai SK, Priyanka P. A rare diagnosis with a common presentation: a case report on uterine sarcoma. Int J Reprod Contracept Obstet Gynecol 2021;10:2498-500. 